\title{
Quantifying the Impact of Lockdown Syndrome - An Emerging Threat to Indian Society
}

\author{
Dr. Anis A. B. Choudhery Ph.D. ${ }^{1}$, Simeen Rumani, Msc $^{2}$ \\ ${ }^{1}$ Department of Zoology, G. M. Momin Women's College, Bhiwandi, District Thane, 421302 Maharashtra, India \\ ${ }^{2}$ Department of Zoology, Sindhu Swadhyay Sanstha, Kalina, University of Mumbai, Maharashtra, India
}

\begin{abstract}
Objective: Scientists throughout the world felt importance and urgency of discovering the nature of the virus and measure the destructive capability of SARS-CoV-2 since its, emergence at Wuhan. The impact quantification of health damages caused by COVID-19 helped us in timely mitigation of pandemic and its treatment. Lockdown is being used by many countries as preventive measures from current epidemic. Indian government also imposed lockdowns at nationwide since $25^{\text {th }}$ March 2020. But containment of human population with fear of affecting from pandemic during 100 days of lockdown impact badly on human health, mental health and caused damage on Indian society which could be study under umbrella of lockdown syndrome. This paper is based on the quantification of impact of lockdown syndrome in various segments of society. Methods: Data from 772 people of selective working classes across the India were interviewed during lockdown and studied their responses with the help of experts to quantify the impact. Results: Our results show that impact is long-lasting and dynamic in nature in Indian society. Migrant workers were found suffering more than any other class, unfortunately it is state of great confusion, not the economic loss which impact badly on their emotional loss and they decided to return back to their villages and just after a month time started back towards cities. Housewives, children and aged section of society suffered much due to lockdown. Conclusion: Society needs to learn, practice and prepare to survive with contagious diseases by using modern technologies. Peaceful coexistence is only solution, otherwise we are well aware that most of medicines has side-effects and sometime side effects are life threatening. Lockdown syndrome is side effect of pandemic control program and causes more damage than the pandemic.
\end{abstract}

Keywords: Pandemic, health status, mental condition, behaviour pattern, Lockdown syndrome, COVID-19

\section{Introduction}

"Lockdown" tactics were developed in the late 1970's in Southern California. A more accurate description of the tactic at that time would be "secure in place "in response to drive-by shootings and street level crimes are occurring outside of school buildings ${ }^{1}$. Later on, it was used during nuclear testing, terrorist attacks and it was frequently used in few of cases of recent epidemic. It is used as preparatory tool and safeguards the society at initial outbreak of the disease. Authorities ensure that no one should come in contact with other, maintain social distancing, no public gathering, no social engagement during lockdown. All the public and private transport system are shut down and special enforce acts are enforced on society. Visibility of normal human at streets becomes negligible and all regular work is at the halt. School, colleges, market, factories are at halt only essential services are allowed with strict vigilance.

A normal family, including children, adult and aged people restricted at their homes irrespective of the area of the house. It may not have any issues for some days, but during 5 consecutive lockdowns in India of more than 100 days it is observed that it impacts on health, mental and economic of our society. The impact was far more than the epidemic itself.

In current pandemic, there are more than 10 million people are affected by disease but $79 \%$ global population is suffering from lockdown. People stressed due to longer quarantine duration as well as infection fears, frustration, boredom, inadequate supplies, inadequate information, financial loss, social stigma ${ }^{2}$. China was the first country to impose strict lockdown in Wuhan city to control the disease.
After nearly 500 confirmed cases in India the central government-imposed lockdown from $25^{\text {th }}$ March 2020, initially for 21 days and further extended for another three months. It was the longest duration of the lockdown for largest population anywhere in the world. Profound, disturbing effect on all aspects of society, including mental health and physical health can be anticipated ${ }^{3}$. Anxiety is the most common mental health disorders in the general population and can be characterised by the feelings of stress and worrying thoughts ${ }^{4}$.The lockdown applied to three main areas 1- No physical movement outside of the home 2- Strict social distancing when outside the home, and 3- restricted availability of most public services while sparing essential services.

There was a sudden and drastic alteration in the daily routine, with many millions stranded in boarding houses and rental apartments, without work and far from home. Academic work ground to a halt, with auxiliary staff like cleaners, security guards and gardeners suddenly being thrown out of their contractual work. Earlier studies have shown that this sudden loss of employment, along with financial stress or even distress, could enhance the psychological impact on the working community, shown by symptoms of increased aggressiveness and post-traumatic stress ${ }^{5}$. Besides, this Pandemic is impacting a population already facing challenges in their lives like unemployment, family issues and various other changes like lifestyle which is included as a significant reason for anxiety ${ }^{6}$.Overall, the investigators found that social isolation and loneliness increased the risk of depression, as well as the possibility of anxiety and mental instability at the time of loneliness. The investigators found young people were as much as 3 times more likely to develop depression in the future due to social 


\section{International Journal of Science and Research (IJSR) \\ ISSN: 2319-7064}

ResearchGate Impact Factor (2018): 0.28 | SJIF (2019): 7.583

isolation, with the impact of loneliness on mental health lasting up to 9 years later $^{7}$.In addition to various psychological problems like depression, anxiety, and panic disorder, the COVID-19 pandemic has caused severe threats to the lives and physical health of people around the globe ${ }^{8}$. Besides the physical problems the Covid-19 gave rise to lock down and Lockdown led to Lockdown-syndrome affecting social and psychological well-being of humans.

\section{Methodology}

The objective of this study was to study and quantify impact of lockdown syndrome during COVID-19 in different sections of the Indian society. Defined cross-section interview conducted as per by Jane Agee ${ }^{9}$, and systematic review was conducted as per framework suggested by Arksey and O'Malley ${ }^{10}$ Several in-depth interviews were done to understand the current situation better. Referring to many social media and research article on COVID-19, questionnaires were framed for online. The questionnaire was designed based on the research questions, after which the stratification and identification of respondent done by a team of research groups.

The online survey conducted from $1{ }^{\text {st }}$ May to June $20^{\text {th }}, 2020$, using an anonymous Google form via social media. After reviewing the pertinent literature which included scales such as, Impact of Event Scale - Revised (IES-R), and the international guidelines, a self-administered, pre-validated web-based questionnaire in English were prepared. The questionnaire includes impact on the lockdown of financial stress, mental stress, emotional stress, depression, health, wellness, anxiety, anger, sleeping disorders, digestion, food intake, domestic violence and social trust.

As per roles, economic status and social class interviewers purposely divided in eight categories which included corporate, middle class having fixed and regular income, doctors and medico-professionals, enforcement agencies, children 5-14 years, housewives, aged persons (above 70 years) and migrant workers. The researchers combined a structured survey and personal interviews of 772 people across the country with the help of experts. Special indexing was created to measure the impact of lockdown. It is termed as a Lockdown Impact Factor (LIF). It ranged between minimum 0 to maximum 10 for each element. Total LIF of 120 points attributed to each category.

The free availability of the tool and automatic recording of user responses in its spreadsheet had made data collection and analysis simple. In a country like India, where the internet user base is increasing day by day web-based survey tools became an obvious choice for survey research. ${ }^{11,12,13}$

\section{Survey implementation}

The survey was implemented in the different cities of India with the help of academicians and friends. Efforts were made to ensure that all respondents were appropriately informed about the study and thoroughly understood their participation in the study was voluntary. Participation and interviewers ensured that participants knew that refusal to participate would not lead to any adverse consequences. During our surveys, we found that lockdown caused greater damage than SARS-CoV-2, sets of symptoms were discrete in different selected categories. Each category was asked to rank between1to10 as per negative impact on human behaviour /mental health /physical health or physiological health. Observation of the present study will certainly provide a base for descriptive research to analyse societal loss of Lockdown in India.

\section{Observation and Results}

It is found that lockdown syndrome can be characterised by a universal group of symptoms which causes damages on human health, mental health as well as negative changes in society. It has broader spectrum than the COVID-19, include corona positive, corona negative and post pandemic population.

Table:01 Showing Lockdown Impact Factor (LIF) on different segments of Society (out of Maximum 10 point)

\begin{tabular}{|c|c|c|c|c|c|c|c|c|c|c|c|c|c|}
\hline $\begin{array}{l}\text { Sample categories } \\
\text { Size }\end{array}$ & $\begin{array}{l}\text { financial } \\
\text { stress }\end{array}$ & $\begin{array}{l}\text { Mental } \\
\text { stress }\end{array}$ & $\begin{array}{l}\text { Emotional } \\
\text { Stress }\end{array}$ & Depression & $\begin{array}{l}\text { Health } \\
\text { wellness }\end{array}$ & Anxiety & $\begin{array}{l}\text { Hyper } \\
\text { tension }\end{array}$ & $\begin{array}{l}\text { Sleeping } \\
\text { Disorders / } \\
\text { insomnia }\end{array}$ & Digestion & $\begin{array}{l}\text { food } \\
\text { Intake }\end{array}$ & $\begin{array}{l}\text { Family } \\
\text { Fight }\end{array}$ & $\begin{array}{l}\text { Social } \\
\text { Trust }\end{array}$ & $\begin{array}{l}\text { Total } \\
\text { LIF }\end{array}$ \\
\hline 40 Corporate & 7 & 4 & 2 & 6 & 2 & 3 & 8 & 7 & 2 & 3 & 7 & 7 & 58 \\
\hline 100 Middle class & 0 & 2 & 2 & 2 & 2 & 2 & 1 & 3 & 4 & 1 & 6 & 6 & 31 \\
\hline $\begin{array}{ll} & \text { Medico } \\
100 & \text { Professional } \\
\end{array}$ & 1 & 6 & 6 & 5 & 10 & 2 & 6 & 6 & 1 & 6 & 1 & 4 & 54 \\
\hline $\begin{array}{l}\text { Enforcement } \\
100 \text { agencies }\end{array}$ & 0 & 7 & 4 & 5 & 5 & 2 & 6 & 5 & 1 & 2 & 1 & 4 & 42 \\
\hline 100 Children 5-14 & 0 & 4 & 4 & 4 & 2 & 4 & 5 & 2 & 6 & 1 & 2 & 8 & 42 \\
\hline 100 Housewives & 5 & 10 & 10 & 10 & 8 & 3 & 8 & 7 & 2 & 5 & 8 & 8 & 84 \\
\hline 32 Aged above 70 & 2 & 10 & 8 & 10 & 8 & 8 & 2 & 8 & 2 & 8 & 2 & 8 & 76 \\
\hline 200 Migrant workers & 10 & 10 & 10 & 10 & 10 & 10 & 9 & 10 & 4 & 9 & 10 & 2 & 104 \\
\hline 772 Category total & 25 & 53 & 46 & 52 & 47 & 34 & 45 & 48 & 22 & 35 & 37 & 47 & \\
\hline
\end{tabular}

In India we found overall impact was very astounding; lockdown causing great uncertainties hopelessness and disturbance in society apart from economic stress. I would like to summarize my findings as following: 


\section{International Journal of Science and Research (IJSR) \\ ISSN: 2319-7064}

ResearchGate Impact Factor (2018): 0.28 | SJIF (2019): 7.583

Entire Indian population is undergoing significant mental challenges like fear of having contagious coronavirus, Isolation of individuals /families due to social distancing, missing all their normal routine and fear of uncertainties. There was a sudden and drastic alteration in the daily routine, with many millions stranded in boarding houses and rental apartments, without work and far from home. Earlier studies have shown that this sudden loss of employment, along with financial stress or even distress, could enhance the psychological impact on the working community, shown by symptoms of increased aggressiveness and post-traumatic stress. Students have been facing various problems related to depression anxiety, poor internet connectivity, and unfavorable study environment at home. Students from remote areas and marginalized sections mainly face enormous challenges for the study during this pandemic ${ }^{14}$.

We found that lockdowns caused great damage in mental health, $47.36 \%$ of people feel high psychological distress even before the end of the first lockdown. Most of the responded above 70 years complained about insomnia and having the fear of getting diseases and die. Migrant workers feel situation won't be normal soon and they may face starvation due to no faith in government, it pushes them into the world's largest inter-state migration of a country towards their town or villages.

1) An extreme level of phobia was witnessed in old aged people. It was higher fear of infection in the elder population due to excessive media presentations and internal discussion of family during lockdown. $63 \%$ of people above 70 years of age (76 LIF) facing a toxic level of stress, mental depression and great loss of social trust leading to hopelessness, mental trauma, hypertension and heart attack. Insomnia or sleeping disorders /disturbance was found in most of this category. They have minimized food intake and shown lots of emotional stress.As per Help Age India survey report of 5,099 elders across 17 states and four Union territories. It found that of those 65 per cent elders whose livelihoods had been impacted. About 71 per cent elder respondents stated that the livelihood of the breadwinner of their family was impacted (loss of work/wages) by the lockdown ${ }^{15}$.
2) Lockdown affected the Indian economy very heavily millions of workers lost their jobs after the extension of first lockdown and rest fear to lose it, as there is no sign of good economic growth in near future. Migrant workers were affected more than any other categories (104 LIF). Most of them lost their Jobs, $86.6 \%$ of migrant workers have lost their appetite and suffering from insomnia, $100 \%$ faced severe depression due to lockdown, overburdened by financial stress, uncertainty, home sickness, withdrawal syndrome, which ultimately directed them towards Mental shock. Hundreds of migrant workers committed suicides during the lockdown period due to financial losses.

3) The study revealed $48.3 \%$ of Corporate /Industrialist with impact factor 58 facing Bankruptcy, withdrawal syndrome, health Issues, physiological and psychological problem, Losing confidence in business, agony and high Blood pressure whilst $35 \%$ of police / $\mathrm{BSF} /$ Home Guard (front line workers) with impact factor $42 \%$ played a very crucial role in implementing the lockdown across India facing mental and physical tiredness and getting expose to Covid-19.

4) The researchers found out that $56 \%$ housewives, experienced exceptional and added stress of dealing with toddlers, serving family, health issues, mental pressure, hypertension, domestic violence, suicide, divorce which impacted psychological well-being, as a result of the lockdown. The health care workers $45 \%$ of them with impact factor 54 are suffering from physically and mentally tired and home sickness due to the constant battle against Covid-19 and dealing with COVID-19 patients.

5) $25.8 \%$ of middle class salaried individual with impact factor of 31 is dealing with family issues and financial stress whereas $35 \%$ children under 14 years of age with impact factor 42 spend most of their time with mobile, watching TV, lacking social trust leading to Loneliness, increase TV screen time, mobile addiction, low confidence, no or less physical activities etc. The use of internet and the change in sleep patterns to survive with the lockdown lead to lockdown syndrome, leaving behind a lasting unsympathetic impact even after the lockdown.

\section{Chart:01 Overall Impact of Lockdown on different section of society}

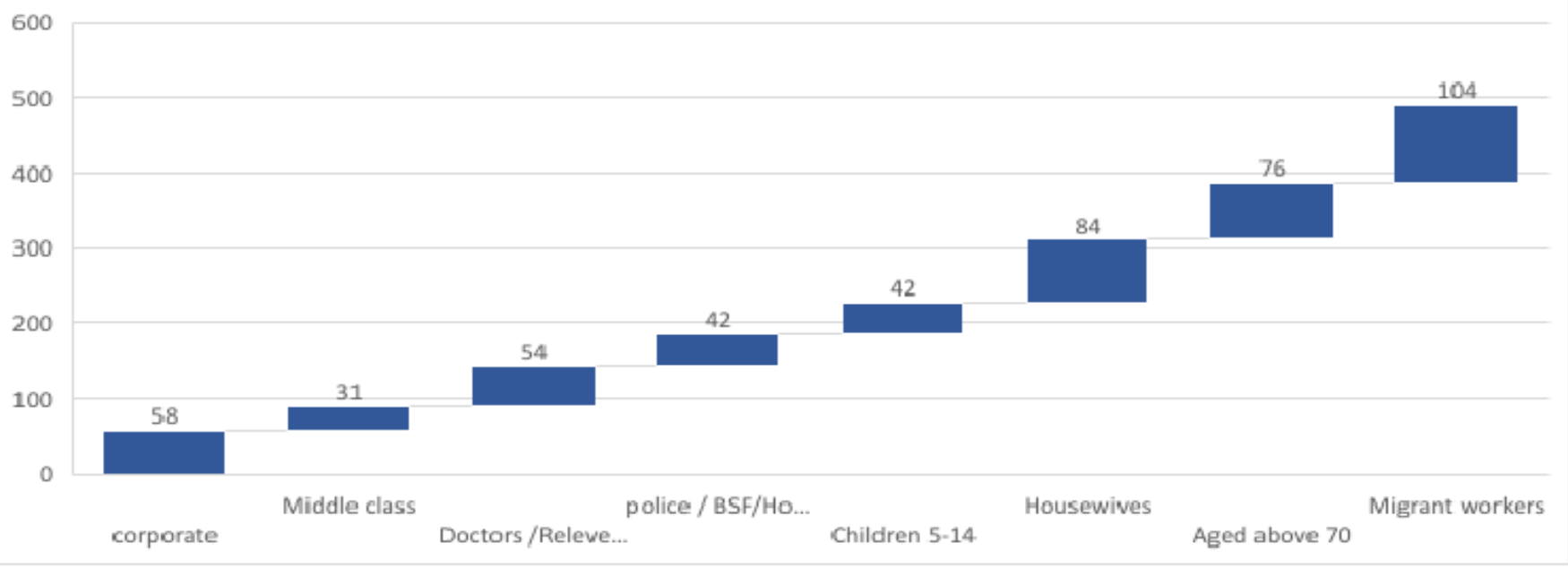

Volume 9 Issue 8, August 2020 www.ijsr.net 


\section{International Journal of Science and Research (IJSR) \\ ISSN: 2319-7064}

ResearchGate Impact Factor (2018): 0.28 | SJIF (2019): 7.583

6) Survey analysis shows that migrant workers have largest sharing of the overall impact of lockdown (21\%) followed by housewives (17\%) (graph 2). Middle class with a fixed source of income are least affected and they share only $6 \%$ of the impact. Aged people have $15 \%$ sharing on graphs. Corporate $12 \%$, doctors and medico staff $11 \%$, enforcement agencies as well as children have $9 \%$ of shares.
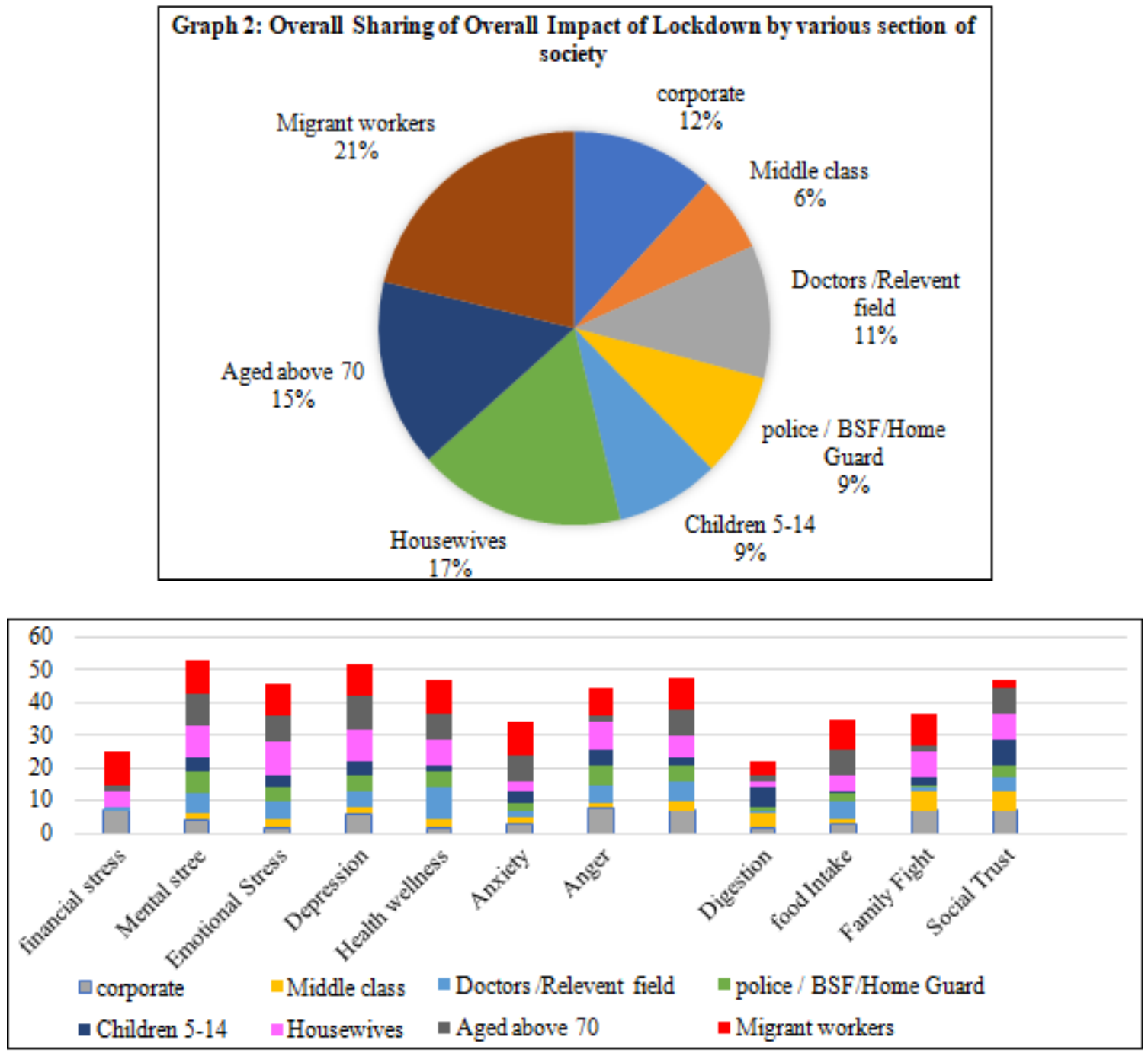

Graph 3: Distribution of various social, psychological and health disorders in different sections of Indian society during lockdown

\section{Inference}

Lock down syndrome caused much greater impact than the pandemic itself, because of the broad spectrum of victims, longer duration and unplanned approach of the authorities. It was an additional burden on inexperienced Indian society. Mental stress, depression and sleeping disorders were most common disorders of lockdown syndrome on almost all the segments. It can be narrowed in collection of symptoms causing social, physical and mental abnormalities.

In social abnormalities it impacts on economic, social trust, religious belief and customs and culture of society. Mental and physical abnormalities, it causes loneliness, mentalstress, insomnia, indigestion, hypertension and confusion. The impact has been observed more severe during middle period, i.e. fourth and fifth nationwide lockdowns between $10^{\text {th }}$ May to $30^{\text {th }}$ May.

\section{Suggestions and Recommendations}

1) Quantifying the impact of current LDS will be useful in fighting pandemic in the future. It needed a nationwide descriptive research.

2) There must be some alternative of complete lockdown like smart lockdown and confined to contentment area. With the help of social media, tele-consultations, online consultations, supported counselling's, developing family associations and interactions can promote resilience in housewives, older aged people and healthcare workers, and make them more convinced in their capability to administer stresses in the future.

3) The mental health system and mental health professionals need to address various problems with solutions. When the Covid-19 catastrophe comes to an end, the psychological health emergency is going to surface, and we must be prepared. 


\section{International Journal of Science and Research (IJSR) \\ ISSN: 2319-7064}

ResearchGate Impact Factor (2018): 0.28 | SJIF (2019): 7.583

4) Conversely, the qualitative part of the study reveals that pliability and good coping strategies helped even highrisk individuals such as people above 70 years of age to stay optimistic. People with old age requires Continuous counselling, engaging in family get-together is a good way to reduce mental stress and depression in aged people.

5) For migrant workers; the study reveals the only positive support they have with them is social trust. Assurance of continuous work and payment during lockdown or partial monetary support and fulfillment of basic need would have been certainly more effectively than anything else.

\section{Financial Support}

This research work received no specific grant from any funding agency, commercial entity or not-for-profit organisation.

\section{Acknowledgement}

I would like to express my deepest appreciation to all those who provided me the possibility to complete this report. A special gratitude I give to, Ms Shaikh Salwa Amir, Ansari Zaibnab and Momin Ruman Latif whose contribution in stimulating suggestions and encouragement, helped me to coordinate my project especially in writing this report.

Furthermore, I would also like to acknowledge with much appreciation the crucial role by Ms. Momin Saleha the manager of Central Hospital -Mumbai India for collection of data from medico related field.

I have to appreciate the guidance given by other supervisor as well as the panels especially in our project presentation that has improved our presentation skills thanks to their comments and advices. We thank all the participants for their voluntary participation and for providing essential information.

\section{Authors' Contributions}

Anis A. B. Choudhery designed the study, developed the questionnaire, collected data and prepare first draft of the paper. Ms. Simeen Rumani helped in analysing statistical data and performed writing-review

\section{References}

[1] Lieutenant Joseph A. Hendry Jr. , CLEE(2009), Origin of Lockdown pages 5-6

[2] S.K.Brooks, et.al, (2020), ThePsychological impact of Quarantine and how to Reduce it: A Rapid review of the Evidence," The Lancet,vol.395,no.10227,pp.912920

[3] E. A. Holmes et al. (2020), "Multidisciplinary research priorities for the COVID-19 pandemic: a call for action for mental health science,".The Lancet Psychiatry, vol. 0366, no. 20, pp. 1-14,

[4] S. F. K. Maideen, S. M. Sidik, L. Rampal, and F. Mukhtar, (2015), "Prevalence, associated factors and predictors of anxiety: A community survey in
Selangor, Malaysia,” BMC Psychiatry, vol. 15, no. 1, pp. 1-12, 2015

[5] Liji Thomas , (2020) How India's lockdown has affected mental health,https://www.newsmedical.net/news/20200527/How-Indias-lockdown-

has-affected-mental-health.aspx Retrieved on 20 June 2020

[6] N. Davis (2020) Urgent studies needed' into mental health impact of coronavirus," The Guardian, 15-Apr2020

[7] Kenny Walter, (2020)COVID-19 Lockdown Having an Impact on Adolescent Mental Health,https://www.mdmag.com/medical-news/covid19-lockdown-adolescent-mental-health. Retrieved on June 2,2020,

[8] Q. Li, X. Guan, P. Wu, et al, (2020) Early transmission dynamics in Wuhan, China, of novel coronavirusinfected pneumonia. Engl. J. Med. (2020) NEJMoa2001316. Epub ahead of print

[9] Jane Agee (2009), Developing qualitative research questions: a reflective process , International Journal of Qualitative Studies in Education, Volume 22, - Issue 4, Pages 431-447

[10] Hilary Arksey \&Lisa O'Malley, (2005)Scoping studies: towards a methodological framework :International Journal of Social Research Methodology, Volume 8 , Issue 1 Pages 19-32

[11] C. Rothe, M. Schunk, P. Sothmann, et.al(2020), Transmission of 2019-nCoV infection from an asymptomatic contact in Germany, N. Engl. J. Med. (2020) NEJMc2001468. Epub ahead of print

[12] $2020 \quad$ Novel Coronavirus (2020)https://www.cdc.gov/coronavirus/2019ncov/about/transmission.htmlGoogle Scholar

[13] ANI, 24 March (2020), Covid-19: People flock to wholesale markets in UP, West Bengal amid lockdown

[14] NanigopalKapasia,et al (2020), Impact of lockdown on learning status of undergraduate and postgraduate students during covid-19 pandemic in West Bengal,India Children and Youth Services Review116.

[15] https://economictimes .indiatimes.com 15 June 2020 